\title{
OPEN Thermal engineering of stone increased prehistoric toolmaking skill
}

Received: 17 May 2019

Accepted: 16 September 2019

Published online: 10 October 2019

\begin{abstract}
Veronica Mraz ${ }^{1}$, Mike Fisch², Metin I. Eren ${ }^{3,4}$, C. Owen Lovejoy ${ }^{3,4}$ \& Briggs Buchanan ${ }^{1}$
Intentional heat treating of toolstone has been documented to have begun at least by $70 \mathrm{~K} \mathrm{BP}$; however, the advantages of such treatment have been debated for decades. There are two schools of thought with regard to its purpose. One, is that it merely reduces the force required for flake propagation. A second is that it also alters flake morphological properties. We systematically tested these hypotheses by generating flakes from cores exposed to three different temperatures (ambient, $300^{\circ} \mathrm{C}$, and $350^{\circ} \mathrm{C}$ ) using automated propagation procedures that bypassed any human agency. While the force propagation magnitude is altered by heat treatment, the flakes were not. We examined these flakes according to nine measures of morphology. None differed significantly or systematically within the three categories. While our results confirm that heat treatment does reduce the force needed for flake propagation, they also demonstrate that such treatment has no significant effect on major morphological aspects of flake form.
\end{abstract}

Archaeologists have long argued that heat treatment improves the quality and workability of toolstone ${ }^{1-8}$. Heat treatment (HT) usually involves slowly heating stones to approximately $200{ }^{\circ} \mathrm{C}$ to $500{ }^{\circ} \mathrm{C}^{9}$, but other strategies have been explored as well (e.g. $\left.{ }^{10}\right)$. The earliest documented case of intentional and systematic HT is from the South African Middle Stone Age, over 72 thousand years ago ${ }^{11-13}$. Since that time, lithic HT has been documented archaeologically and ethnographically throughout the world (e.g. ${ }^{12,14}$ ).

The mineralogical, chemical, and crystallographic effects of relatively high heat applied to stone have been examined thoroughly (e.g ${ }^{13,15-22}$.). However, Schmidt et al.'s ${ }^{14}$ critical review has highlighted a current gap in our understanding of its effect on stone fracture mechanics. This is critical because stone's "workability" may have been the potential conscious or subconscious primary target of HT by earlier humans. Indeed, as Wadley and Prinsloo ${ }^{13}$ and Schmidt et al. ${ }^{14}$ outline, HT has been linked to the evolution of complex human behavior and cognition, technical skill, and specialized craftsmanship ${ }^{11,23-31}$.

Heat treatment has been argued to improve the workability of stone for knapping essentially in two ways. The first is that it purportedly reduces the force magnitudes needed to initiate fracture ${ }^{17,18,32-36}$. This has been robustly supported by direct observation via materials testing, as well as by quantitative assessments of force required to detach flakes ${ }^{11,12,14,37-40}$. The second is that it may alter the size and shape of flakes removed from a core ${ }^{41-45}$. For example, Bleed and Meier ${ }^{33}$ have suggested that heat-treated flakes are larger and longer than flakes removed from "raw" (i.e., untreated) cores. Likewise, Cooper ${ }^{46}$ has suggested that heat-treated stone yields larger flakes than its untreated counterpart, while Hanckel ${ }^{47}$ has opined that flakes produced from heat-treated stone are thinner than are those removed from untreated material. Moreover, Collins and Fenwick ${ }^{48}$ have suggested that heat-treated flakes are less variable in form than are raw ones, as they purportedly have fewer step and hinge terminations. Flenniken and Garrison ${ }^{49}$ also assert that a knapper has potentially more control of the form of flakes removed from a HT core than from a "raw" one. Finally, Rick and Chappell ${ }^{45}$ have argued that heat-treated flakes are sharper than their raw counterparts because they putatively bear more acute edge angles than do flakes derived from unheated cores.

Following Eren et al. ${ }^{50}$, one can argue that HT interacts with other input variables in two different hypothetical ways, which constitute polar opposites. The first or "natural forces" hypothesis ${ }^{51,52}$ posits that artifact morphology

\footnotetext{
${ }^{1}$ Department of Anthropology, University of Tulsa, Tulsa, Oklahoma, 74104, USA. ${ }^{2}$ College of Aeronautics and Engineering, Kent State University, Kent, Ohio, 44242, USA. ${ }^{3}$ Department of Anthropology, Kent State University, Kent, Ohio, 44242, USA. "Department of Archaeology, Cleveland Museum of Natural History, Cleveland, Ohio, 44106, USA. Correspondence and requests for materials should be addressed to B.B. (email: briggs-buchanan@ utulsa.edu)
} 
depends exclusively on whether core stone is raw or heat treated when knapped. A corollary is that behavioral and cultural factors play no role in determining artifact form, and that natural stone constrains or "dictates" artifact morphology. The contrary view is represented by the "artificial forces" hypothesis ${ }^{51,52}$. This holds that HT has no substantial effect on artifact morphology, which instead lies only with its knappers. This hypothesis holds that there is nothing inherently different about raw versus heat-treated rock types that can influence artifact morphology-artifact form ultimately lies only with knappers themselves.

One way to assess these two hypotheses is to perform a flintknapping experiment in which human influence has been removed from flake production ${ }^{53-56}$. Previous experimenters have attempted to do this, but with only limited results. For example, Bleed and Meier's ${ }^{33}$ experiment rolled raw and heat-treated stone tiles in a mechanical drum. However, this mimics geologic processes more closely than flintknapping. Cooper ${ }^{46}$ dropped ball bearings on slabs of raw and heat-treated stone, but he examined only ten samples of each, and reassessment of his flake morphology data contradicts his conclusion that HT increases flake size (see Cooper ${ }^{46}$ :Table 1).

To overcome these limitations, we produced flakes from raw and two types of heat-treated cores using an Instron Universal Materials tester, and then compared their form within three datasets as defined by the temperatures of their heat treatment. Of major import is our ability to determine the magnitude of the force required to initiate flake fracture independent of any human agency other than HT itself. Our experiment has allowed us to demonstrate that HT cores exhibit less resistance to fracture propagation (i.e, less energy is required to generate fracture and they are thus less tough than are raw cores). This has allowed us to examine whether toughness alone consistently leads to different flake forms, which in turn has provided us an opportunity to reliably test the natural versus artificial force hypotheses.

\section{Results}

We first examined the force magnitudes required to detach flakes in each of the three test groups. Their distributions do not significantly differ from an underlying normal distribution (Shapiro-Wilk test $\mathrm{W}=0.99, \mathrm{p}=0.7396$ ). Boxplots show that the force magnitudes required to detach flakes from the raw (ambient) cores appear to be greater than those required to remove flakes from cores heated either to $300^{\circ} \mathrm{C}$ or to $350^{\circ} \mathrm{C}$ (Fig. 1). The ANOVA of the force data by core group supports this observation $(\mathrm{F}=4.522, \mathrm{df}=2,87, \mathrm{p}=0.0135)$. Multiple comparisons using Tukey's HSD method indicate that the force needed to remove flakes from raw cores is significantly greater than the force required to detach flakes from cores heated to $350^{\circ} \mathrm{C}$ (difference $535.33, \mathrm{p}=0.009$ ), but the force used to remove flakes from raw cores and cores heated only to $300^{\circ} \mathrm{C}$ did not differ significantly (difference $249.08, \mathrm{p}=0.3464)$. The forces required to remove flakes from cores heated to $300^{\circ} \mathrm{C}$ and $350^{\circ} \mathrm{C}$ also do not differ significantly (difference $286.25, \mathrm{p}=0.2483$ ).

We next added platform depth and exterior platform angle as variables in our analysis of force magnitude, as both variables have been reported to affect flake $\operatorname{size}^{57-63}$. It is therefore also likely that they affect the magnitude of force required to detach flakes. The sample distributions of platform depth $(\mathrm{W}=0.96, \mathrm{p}=0.0046)$ and exterior platform angle $(\mathrm{W}=0.97, \mathrm{p}=0.0447$ ) differ significantly from an underlying normal one (exterior platform angle is only borderline significant). Transformations of the platform depth and exterior platform angle variables did not result in normality. Given this non-normality of some variables, we used a nonparametric ANCOVA to control for interaction between platform depth and exterior platform angle, while examining differences in mean force magnitude among the three core groups. Our results suggest a significant difference in force required to detach flakes among the three treatment groups $(h=18.93, \mathrm{p}=0.0337)$. Figure 2 shows the relationships among the three variables and core groups. The force needed to remove flakes from cores heated to $300{ }^{\circ} \mathrm{C}$ shows some interaction with the force needed to remove those from raw cores in both the linear (Fig. 2a) and smoothed (Fig. 2b) fit lines. The cores heated to $350{ }^{\circ} \mathrm{C}$ required less force to remove flakes after controlling for exterior platform angle and platform depth.

Following the analyses of force magnitude differences, we examined the potential differences in flake form amongst the three test groups. We first examined differences in flake form by temperature group without regard of the differences in force necessary to detach the flakes. We did this because we are interested in the morphology of the flakes given the same starting condition of initial detachment. Tests of normality indicate that only maximum thickness differs significantly from an underlying normal distribution (Table 1). Logarithmic and square root transformations of thickness measures did not reduce the skewness in the sample distribution. Accordingly, we carried out ANOVA tests for six of the variables (weight, length, maximum width, width at $25 \%$, width at $50 \%$, and width at 75\%) and a Kruskal-Wallis nonparametric test for one variable (maximum thickness) by core group. The results indicate that none of the measurement variables differed among the core groups (Table 2) and that the Kruskal-Wallis test indicates that thickness also did not differ among core groups (K-W chi-square $=1.047$, $\mathrm{p}=0.5923)$. Additionally, Kruskal-Wallis tests of platform depth and exterior platform angle suggest no differences among core types (Platform depth: K-W chi-square $=2.804, \mathrm{p}=0.2462$; Exterior platform angle: $\mathrm{K}-\mathrm{W}$ chi-square $=0.8922, \mathrm{p}=0.6401)$.

Lastly, we compared the form of flakes by temperature group using a general linear modeling approach to control for force, exterior platform angle, and platform depth. The results of these analyses demonstrate that flake form does not differ across temperature group when force, exterior platform depth, and platform depth are included in the models (GLM results presented in the Supplementary Materials). We conducted further analyses of the seven flake variables using nonparametric ANCOVAs with force and platform depth and force and exterior platform angle as covariates. The results show that none of the variables are significant among the temperature groups (Table 3). Thus, there are no morphological differences among the flakes by temperature group when force, platform depth, and exterior platform angle are considered simultaneously. 


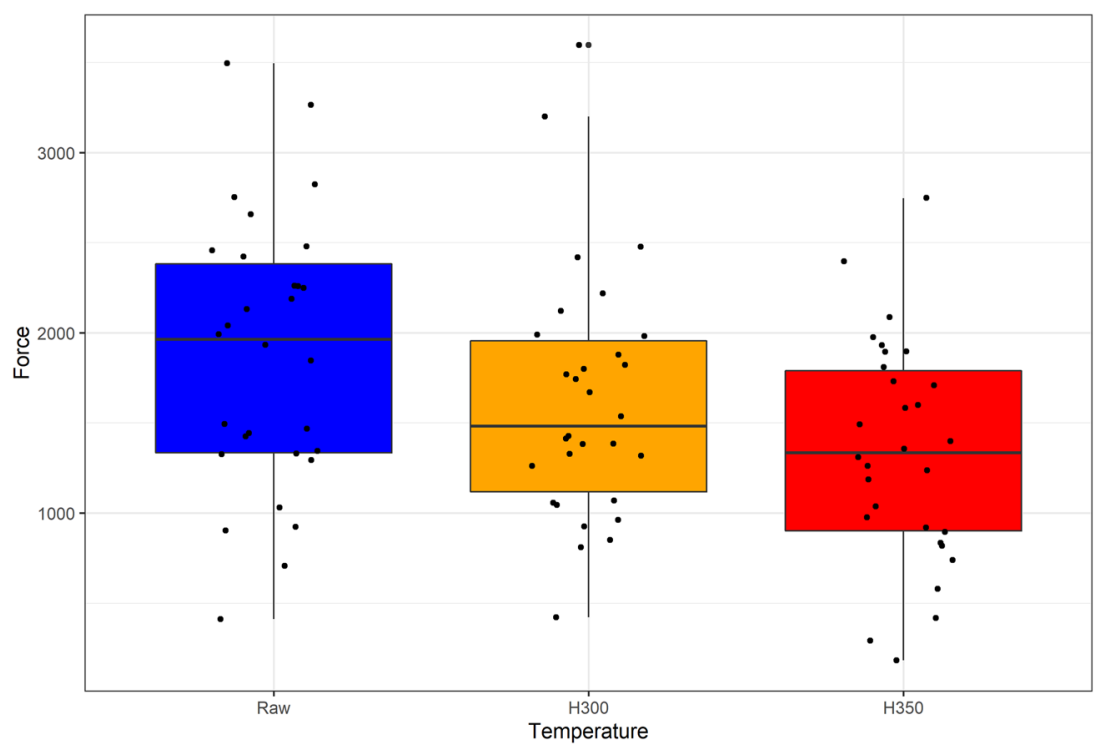

Figure 1. Boxplots of the force needed to detach experimental flakes by temperature (from raw cores [blue box], cores heated to $300^{\circ} \mathrm{C}$ [orange box], and cores heated to $350^{\circ} \mathrm{C}$ [red box]). The bars indicate the median, the boxes show the upper and lower quartiles of the data distribution, and the whiskers show the distributions without outliers. The data are shown as black circles.

\begin{tabular}{|l|l|l|}
\hline Variable & W & P \\
\hline Weight & 0.9792 & 0.1594 \\
\hline Length & 0.9767 & 0.1048 \\
\hline Width & 0.9829 & 0.287 \\
\hline Width at 25\% length & 0.9736 & 0.064 \\
\hline Width at 50\% length & 0.9736 & 0.1521 \\
\hline Width at 75\% length & 0.9813 & 0.2231 \\
\hline Thickness & 0.4884 & $<0.0001 *$ \\
\hline
\end{tabular}

Table 1. Results of Shapiro-Wilk tests for normality for the seven variables measuring the experimentallyproduced flakes from the three core groups. *Benjamini and Yekutieli ${ }^{73}$ adjusted significance level for 7 tests is 0.01928 .

\begin{tabular}{|l|l|l|}
\hline Variable & F & P \\
\hline Weight & 0.122 & 0.885 \\
\hline Length & 1.285 & 0.282 \\
\hline Width & 0.493 & 0.613 \\
\hline Width at 25\% length & 1.553 & 0.218 \\
\hline Width at 50\% length & 0.442 & 0.644 \\
\hline Width at 75\% length & 0.224 & 0.800 \\
\hline
\end{tabular}

Table 2. ANOVA results for the six variables measuring the experimentally-produced flakes from the three core groups.

\section{Discussion}

The heat treatment of stone is a potentially transformative procedure commonly thought to be among the earliest human efforts to alter the properties of naturally available materials ${ }^{11,13,14,64}$. Several studies, including this one, have demonstrated that HT reduces the amount of force necessary to initiate flake fracture from a core. Yet the influence of this transformation on stone flake morphology has, until now, remained unknown.

Our experimental results showed no significant difference between the forms of raw versus heat-treated stone flakes both with and without the covariates of force magnitude, platform depth, and exterior platform angle. This suggests that HT does not alter flake form. Or, more precisely, HT does not render stone more "functional" $28,65$. Both HT and "raw" stone yielded virtually identical flake forms. Therefore, any failure to obtain a desired product lies merely with a knapper's knowledge, manual dexterity, and skill. As such HT merely serves as a "process 
A)

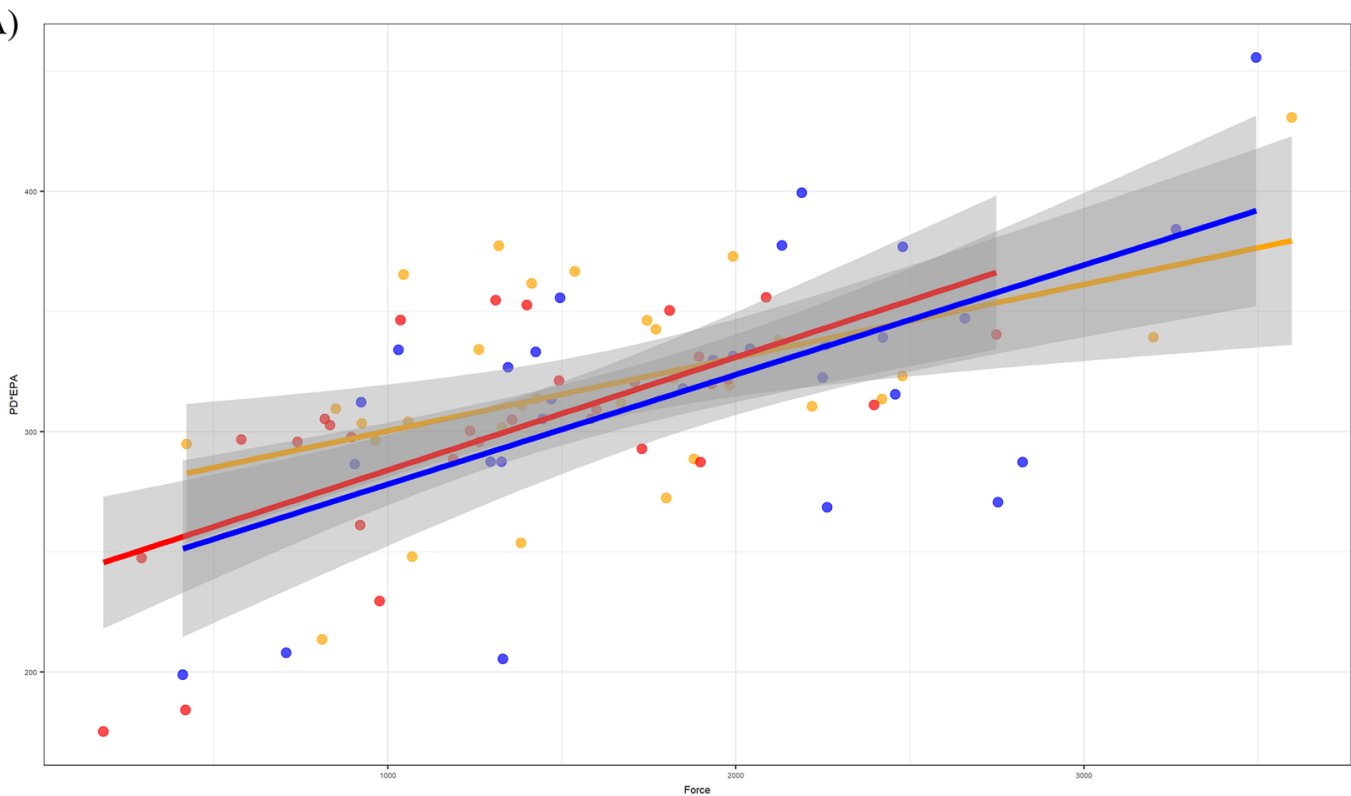

B)

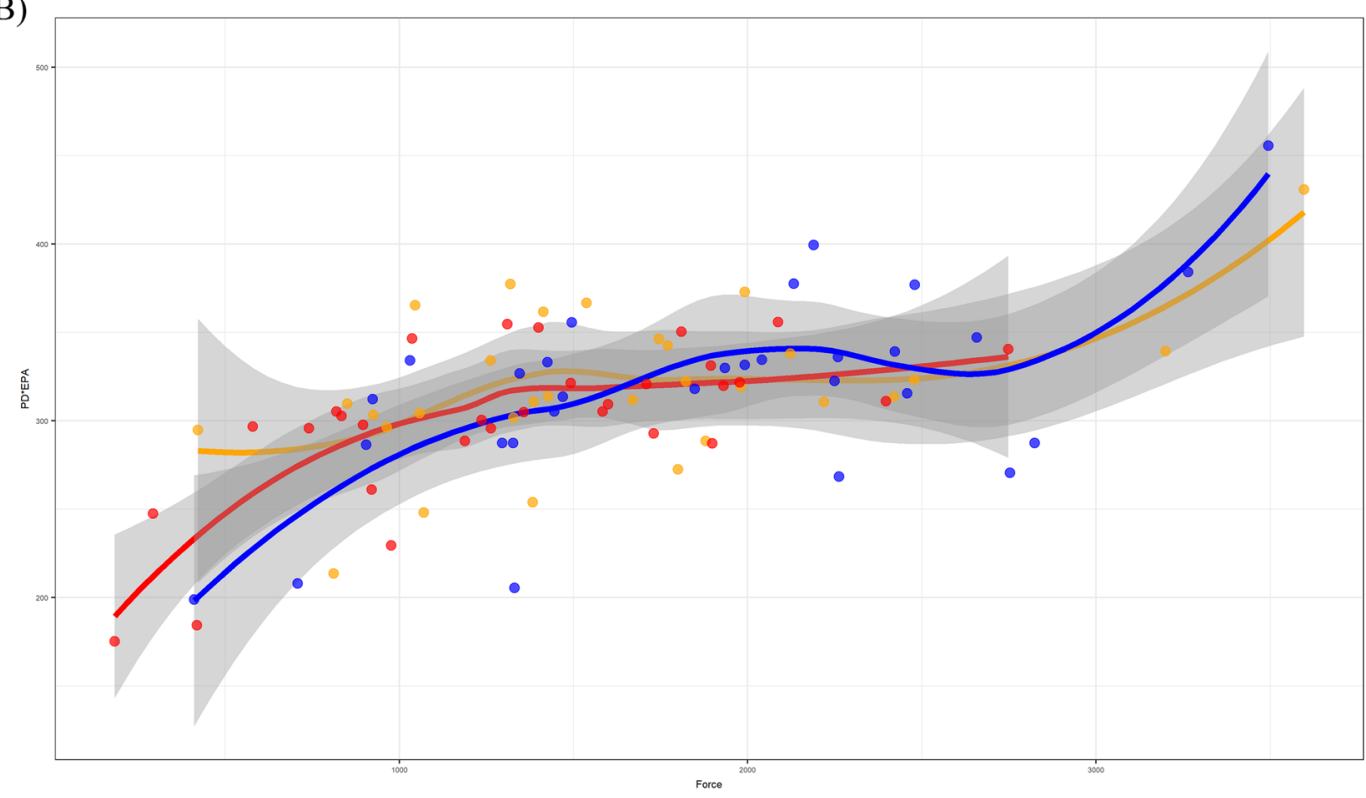

Figure 2. Plot of the ANCOVA results showing (a) linear fit lines, and (b) smoothed lines modelling the relationship between the interaction between exterior platform angle and platform depth and force by core group (flakes derived from raw cores are shown as blue circles, flakes derived from cores heated to $300^{\circ} \mathrm{C}$ are orange circles, and flakes derived from cores heated to $350^{\circ} \mathrm{C}$ are red circles).

\begin{tabular}{|l|l|l|l|}
\hline Covariates = Force + Platform depth & p-value & $\begin{array}{l}\text { Covariates = Force + Exterior } \\
\text { platform angle }\end{array}$ & p-value \\
\hline Weight $\sim$ Temperature & 0.942 & Weight $\sim$ Temperature & 0.6773 \\
\hline Length $\sim$ Temperature & 0.7086 & Length $\sim$ Temperature & 0.5376 \\
\hline Width $\sim$ Temperature & 0.9875 & Width $\sim$ Temperature & 0.6852 \\
\hline Width at $25 \% \sim$ Temperature & 0.9362 & Width at $25 \% \sim$ Temperature & 0.8483 \\
\hline Width at 50\% Temperature & 0.9868 & Width at 50\% Temperature & 0.7736 \\
\hline Width at 75\% Temperature & 0.9499 & Width at $75 \% \sim$ Temperature & 0.6357 \\
\hline Thickness $\sim$ Temperature & 0.9704 & Thickness $\sim$ Temperature & 0.9996 \\
\hline
\end{tabular}

Table 3. Results of nonparametric analysis of covariance with force magnitude and platform depth and force magnitude and exterior platform angle by temperature group. 

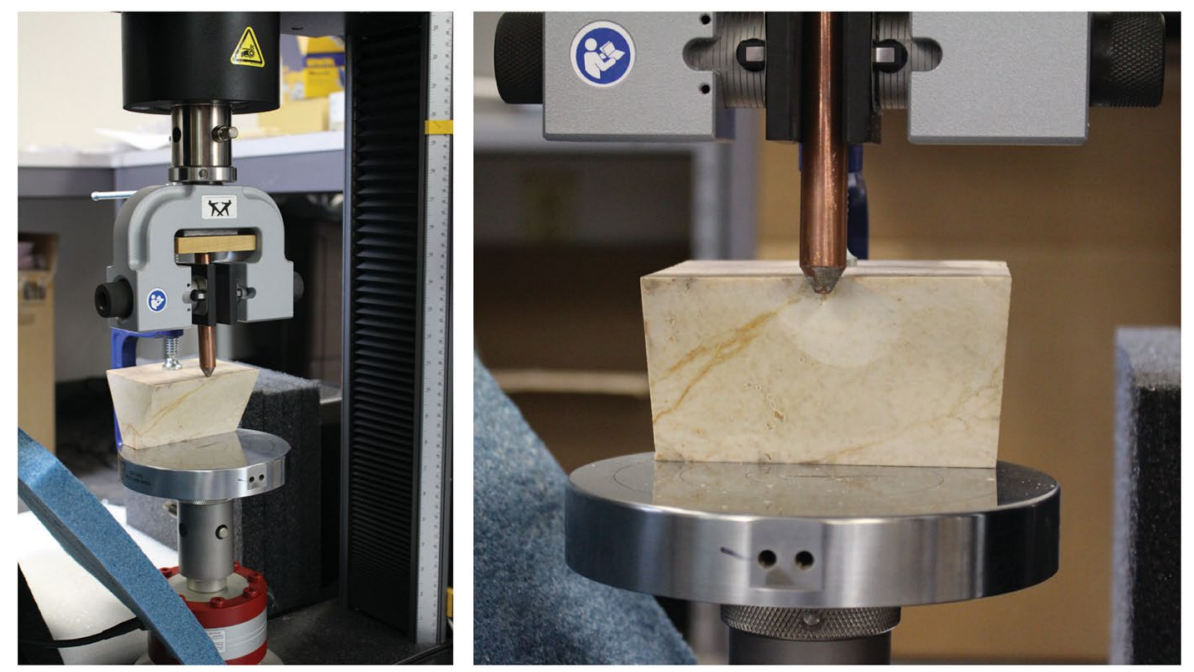

Figure 3. Photographs of the Instron Universal Testing Machine with Keokuk chert core clamped in place. (A) core clamped in Instron prior to flake removal with copper indentor, (B) close-up of core in the Instron after flake is detached with copper indentor.

control", which Patten ${ }^{66}$ has defined as a systematic modification of a process that augments a knapper's skill. Heat treatment certainly adds time and energy to knapping, but by reducing a stones' resistance to fracture propagation $^{14}$ it augments a knapper's skill by lowering arm acceleration, and thus the force needed to generate a crack. This, in turn, allows him or her to focus on the precision and accuracy of blows. That is, HT facilitates the knapping process, but does not alter or potentially improve the flakes it produces. Thus, our findings reject the "natural forces" hypothesis and support the "artificial forces" hypothesis. Artifact morphology lies only with a knapper's skill and knowledge.

Finally, our finding that force magnitude has no impact on flake form is supported by other experiments. Controlled experiments using glass have shown similar results so long as other independent variables such as exterior platform angle, platform depth, and angle of blow are held constant $\mathrm{t}^{59}$. In other words, these three variables dictate flake form even when they are produced by significantly different magnitudes of fracture initiation force. When our results are considered in light of previous controlled knapping experiments, we can suggest more broadly that conchoidal fracture propagation is similar among different kinds of toolstones, although future tests should assess the universality of our heat-treatment results on non-chert toolstones like silcrete or quartzite. The only factor that differs is the amount of force needed to generate a crack. Thus, the reduction in force magnitude that HT renders does not appear to alter the primacy of other variables in stone flake formation; it simply allows knappers to focus on these variables during a strike. Heat treatment can enhance a knapper's skill, but it does not "improve" the stone.

\section{Methods}

We used 47 standardized chert cores in our experiments. All were of Keokuk, a white to gray chert with a medium-grained texture, but which can range in quality from coarse to fine with a dull luster ${ }^{67,68}$. Keokuk is deposited in discontinuous bedded planes of the Boone Formation that are exposed in southeastern Iowa, southwestern Missouri, northern Arkansas, and northeastern Oklahoma ${ }^{69,70}$. We used trapezoidal cores with average lengths of approximately $110 \mathrm{~mm}$ and breadths of $80 \mathrm{~mm}$ wide at the top and $20 \mathrm{~mm}$ wide at the bottom (see SOM). We heated 15 of these cores to $300^{\circ} \mathrm{C}$ and 15 to $350^{\circ} \mathrm{C}$ (see below). We also used 17 raw (ambient) cores. We obtained two flakes from each of the large faces of each core, except in two cases when only one flake each was detached from two raw cores. This produced a sample of 90 flakes, 30 in each temperature group: raw, $300^{\circ} \mathrm{C}$, and $350^{\circ} \mathrm{C}$. The cores had an exterior edge angle of approximately $65^{\circ}$ (the exterior edge angle varied between $60^{\circ}$ and $67^{\circ}$; this variation was due to the difficulty in cutting the cores precisely). We chose this target exterior edge angle in order to be consistent with previous experiments that found it to be effective for removing flakes ${ }^{56,57,59,60,70}$.

We used a Paragon Sentry 2.0 kiln (programmed in Fahrenheit) to heat-treat two groups of cores (SOM). For the experimental flake removal we used an Instron Universal Materials Tester, which simultaneously recorded the force needed to detach each flake (Fig. 3, see also SOM). Prior to detaching each flake we inscribed a line $3 \mathrm{~mm}$ from the lateral edge of each core as a target for the indentor. As the indentor's point was blunt we simply visually centered it on the inscribed line. We programmed the Instron to perform at a velocity of $1000 \mathrm{~mm} / \mathrm{min}$.

Following the protocol of Buchanan et al. ${ }^{71}$, we measured nine variables on each of the 90 flakes generated in our sample. These were as follows: platform depth, exterior platform angle, weight, length (measured from the platform orthogonally to the termination), maximum width (taken at the widest point orthogonal to the length measurement), width at $25 \%$ of length, width at $50 \%$ of length, width at $75 \%$ of length, and maximum thickness.

We separately analyzed two data sets that we obtained from the Instron and the resulting flakes from the Instron experiment. We first examined only the force magnitudes required to remove flakes from the three groups of cores (raw, $300^{\circ} \mathrm{C}$, and $350^{\circ} \mathrm{C}$ ). We then analyzed the form of removed flakes from each group using separate procedures. 
For each analysis we assessed normality using Shapiro-Wilk tests $\mathrm{s}^{72}$ and ran univariate parametric and, where appropriate, nonparametric ANOVAs by core group. For multiple tests we used Benjamini and Yekutieli's ${ }^{73}$ (also $\mathrm{see}^{74}$ ) method to adjust the significance level. For our examination of the simple force magnitude experiment we followed our univariate tests with a nonparametric ANCOVA model design ${ }^{75}$ to test for differences in force magnitude needed to detach flakes analyzed by core group and also to examine any role of platform depth and exterior platform angle, as these variables are known to affect flake size ${ }^{57-63}$.

For our examination of flake morphology, we first conducted univariate comparisons of seven flake morphological variables and two flake platform characteristics by temperature group. Following the univariate analyses of the flake variables we used general linear modeling to evaluate the relative effects of each variable with force magnitude, platform depth, and exterior platform angle included as covariates. We then subjected the variables to nonparametric ANCOVA analyses as described above using force magnitude and platform depth as covariates in one set of analyses and force magnitude and exterior platform angle in the second set of analyses. We conducted all of our statistical analyses using $\mathrm{R}$ version $3 \cdot 5 \cdot 1^{76}$ and RStudio version 1.1.456 $6^{77}$. The data and $\mathrm{R}$ script for analyses are provided in the Supplementary Materials.

\section{References}

1. Bordes, F. Traitement thermique du silex au Solutreen. Bull Soc Pre hist Fr 66, 197 (1969).

2. Crabtree, D. E. \& Butler, B. R. Notes on experiment in Flint knapping: heat treatment of silica materials. Tebiwa 7, 1-6 (1964).

3. Gregg, M. L. \& Grybush, R. J. Thermally altered siliceous stone from prehistoric contexts: intentional versus unintentional alteration. American Antiquity 41, 189-192 (1976).

4. Holmes, D. L. The Predynastic lithic industries of Badari, Middle Egypt: New perspectives and inter-regional relations. World. Archaeology 20, 70-86 (1988).

5. Joyce, D. J. Heat treatment of alibates chalcedony. Lithic Technology 14, 36-40 (1985).

6. Lee, K. Experimental heat-treatment of flint. Lithics 22, 39-44 (2001).

7. Pavlish, L. A. \& Sheppard, P. J. Thermoluminescent determination of Paleoindian heat treatment in Ontario, Canada. American Antiquity 48, 793-799 (1983)

8. Shippee, J. M. Was flint annealed before flaking. Plains Anthropologist 8, 271-272 (1963)

9. Luedtke, B. E. An Archaeologist's Guide to Chert and Flint (Archaeological Research Tools 7, Institute of Archaeology, University of California, Los Angeles 1992).

10. Mercieca, A. \& Hiscock, P. Experimental insights into alternative strategies of lithic heat treatment. Journal of Archaeological Science 35, 2634-2639 (2008).

11. Brown, K. S. et al. Fire as an engineering tool of early modern humans. Science 325, 859-862 (2009).

12. Domanski, M. \& Webb, J. A review of heat treatment research. Lithic Technology 32, 153-194 (2007).

13. Wadley, L. \& Prinsloo, L. C. Experimental heat treatment of silcrete implies analogical reasoning in the Middle Stone Age. Journal of Human Evolution 70, 49-60 (2014).

14. Schmidt, P., Buck, G., Berthold, C., Lauer, C. \& Nickel, K. G. The mechanical properties of heat-treated rocks: a comparison between chert and silcrete. Archaeological and Anthropological Sciences 1-18, https://doi.org/10.1007/s12520-018-0710-y (2018).

15. Frick, J. A., Hoyer, C. T., Herkert, K. \& Floss, H. Comparative heating experiments on flint from the Côte Chalonnaise, Burgundy, France. Anthropologie 50, 295-322 (2012).

16. Hurst, S., Cunningham, D. \& Johnson, E. Experiments in Late Archaic methods of heat-treating Ogallala Formation quartzarenite clasts along the Southern High Plains eastern escarpment of Texas. Journal of Archaeological Science: Reports 3, 207-215 (2015).

17. Purdy, B. A. Investigations concerning the thermal alteration of silica minerals: an archaeological approach. Tebiwa 17, 37-66 (1974).

18. Purdy, B. A. \& Brooks, H. K. Thermal alteration of silica minerals: an archaeological approach. Science 173, 322-325 (1971).

19. Schmidt, P. et al. Crystallographic and structural transformations of sedimentary chalcedony in flint upon heat treatment. Journal of Archaeological Science 39, 135-144 (2012).

20. Schmidt, P. et al. Heat treatment in the South African Middle Stone Age: temperature induced transformations of silcrete and their technological implications. Journal of Archaeological Science 40, 3519-3531 (2013).

21. Schmidt, P., Léa, V., Sciau, P. \& Fröhlich, F. Detecting and quantifying heat treatment of flint and other silica rocks: a new nondestructive method applied to heat-treated flint from the Neolithic Chassey culture, Southern France. Archaeometry 55, 794-805 (2013).

22. Schmidt, P., Lauer, C., Buck, G., Miller, C. E. \& Nickel, K. G. Detailed near-infrared study of the 'water'-related transformations in silcrete upon heat treatment. Physics and Chemistry of Minerals 44, 21-31 (2017).

23. Delagnes, A. et al. Early evidence for the extensive heat treatment of silcrete in the Howiesons Poort at Klipdrift shelter (layer PBD, $65 \mathrm{ka})$, South Africa. PLoS One 11, e0163874 (2016).

24. Inizan, M. L. \& Tixier, J. L'émergence des arts du feu: le traitement thermique des roches siliceuses. Pale orient 26, 23-36 (2001).

25. Léa, V. Raw, pre-heated or ready to use: discovering specialist supply systems for flint industries in mid-Neolithic (Chassey culture) communities in southern France. Antiquity 79, 1-15 (2005).

26. Mourre, V., Villa, P. \& Henshilwood, C. S. Early use of pressure flaking on lithic artifacts at Blombos cave, South Africa. Science 330 , 659-662 (2010).

27. Porraz, G. et al. Technological successions in the Middle Stone Age sequence of Diepkloof rock shelter, Western Cape, South Africa. J. Archaeol. Sci. 40, 3376-3400 (2013).

28. Schmidt, P. \& Mackay, A. Why was silcrete heat treated in the Middle Stone Age? an early transformative technology in the context of raw material use at Mertenhof Rock Shelter, South Africa. PLoS One 11, 1-16, https://doi.org/10.1371/journal.pone.0149243 (2016).

29. Schmidt, P. et al. A previously undescribed organic residue sheds light on heat treat- ment in the middle stone age. J. Hum. Evol. 85, 22-34 (2015).

30. Tiffagom, M. Témoignages d'un traitement thermique des feuilles de laurier dans le Solutréen supérieur de la grotte du Parpalló (Gandia, Espagne). Pale o 10, 147-161 (1998).

31. Wadley, L. Recognizing complex cognition through innovative technology in Stone Age and Palaeolithic Sites. Camb. Archaeol. J. 23, 163-183 (2013).

32. Ahler, S. A. Heat treatment of Knife River flint. Lithic Technology 12, 1-8 (1983).

33. Bleed, P. \& Meier, M. An objective test of the effects of heat treatment of flakeable stone. American Antiquity 45, 502-507 (1980).

34. Ray, J. H. The effects of heat treatment of cherts from the Truman Reservoir. The Missouri Archaeologist 43, 67-85 (1982).

35. Sollberger, J. B. \& Hester, T. R. Some additional data on the thermal alteration of siliceous stone. Bulletin of the Oklahoma Anthropological Society 21, 181-185 (1973).

36. Speer, C. Understanding the effects of heat treatment on Edwards Plateau chert. Ethnoarchaeology 2, 153-172 (2010).

37. Domanski, M. \& Webb, J. A. Effect of heat treatment on siliceous rocks used in prehistoric lithic technology. J. Archaeol. Sci. 19, 601-614 (1992). 
38. Domanski, M., Webb, J. A. \& Boland, J. Mechanical properties of stone artefact materials and the effect of heat treatment. Archaeometry 36, 177-208 (1994).

39. Domanski, M. et al. Heat treatment of polish flints. J. Archaeol. Sci. 36, 1400-1408 (2009).

40. Schindler, D. L., Hatch, J. W., Hay, C. A. \& Bradt, R. C. Aboriginal thermal alteration of a Central Pennsylvania Jasper: analytical and behavioral implications. American Antiquity 47, 526-544 (1982).

41. Mandeville, M. D. \& Flenniken, J. J. A Comparison of the flaking qualities of Nehawka Chert: before and after thermal pretreatment. Plains Anthropologist 19, 146-148 (1974).

42. Olausson, D. Flint and Groundstone Axes in the Scanian Neolithic. An Evaluation of Raw Materials Based on Experiment (CWK Gleerup, 1983).

43. Patterson, L. W. Quantitative characteristics of debit age from heat treated chert. Plains Anthropologist 24, 255-259 (1979).

44. Patterson, L. W. Thermal damage of chert. Lithic Technology 20, 72-80 (1995).

45. Rick, J. W. \& Chappell, S. Thermal alteration of silica materials in technological and functional perspective. Lithic technology 12, 69-70 (1983).

46. Cooper, C. C. A study of the morphological changes in Tiger chert resulting from heat treatment. Lithic Technology 27, 153-160 (2002).

47. Hanckel, M. Hot rocks: heat treatment at Burrill Lake and Currarong, New South Wales. Archaeol. Ocean. 20, 98-103 (1985).

48. Collins, M. B. \& Fenwick, J. M. Heat treating of chert: methods of interpretation and their application. Plains Anthropologist 19, 134-145 (1974)

49. Flenniken, J. J. \& Garrison, E. G. Thermally altered novaculite and stone tool manufacturing techniques. Journal of Field Archaeology 2, 125-131 (1975).

50. Eren, M. I., Roos, C. I., Story, B. A., von Cramon-Taubadel, N. \& Lycett, S. J. The role of raw material differences in stone tool shape variation: an experimental assessment. Journal of Archaeological Science 49, 472-487 (2014).

51. Costa, A. G. A geometric morphometric assessment of plan shape in bone and stone Acheulean bifaces from the Middle Pleistocene site of Castel di Guido, Latium, Italy. In: New Perspectives on Old Stones: Analytical Approaches to Paleolithic Technologies, eds Lycett, S. J. \& Chauhan, P. R., pp. 23-41 (Springer, New York, 2010).

52. de la Torre, I. The early Stone Age lithic assemblages of Gadeb (Ethiopia) and the developed Oldowan/early Acheulean in East Africa. J. Hum. Evol. 60, 768-812 (2011).

53. Lycett, S. J. \& Eren, M. I. Levallois lessons: the challenge of integrating mathematical models, quantitative experiments and the archaeological record. World Archaeology 45, 519-538 (2013).

54. Leader, G., Abdolahzadeh, A., Lin, S. C. \& Dibble, H. L. The effects of platform beveling on flake variation. Journal of Archaeological Science: Reports 16, 213-223 (2017).

55. Lin, S. C., Rezek, Z. \& Dibble, H. L. Experimental design and experimental inference in stone artifact archaeology. Journal of Archaeological Method and Theory 25, 663-688 (2018).

56. Rezek, Z., Lin, S. C. \& Dibble, H. L. The role of controlled experiments in understanding variation in flake production. In: Archaeological Variability and Interpretation in Global Perspective, eds Sullivan, A. P. \& Olszewski, D. I., pp. 307-320 (University Press of Colorado, Boulder, 2016).

57. Dibble, H. Platform variability and flake morphology: a comparison of experimental and archaeological data and implications for interpreting prehistoric lithic technological strategies. Lithic Technology 22, 150-170 (1997).

58. Dibble, H. \& Pelcin, A. The effect of hammer mass and velocity on flake mass. Journal of Archaeological Science 22, 429-439 (1995).

59. Dibble, H. \& Rezek, Z. Introducing a new experimental design for controlled studies of flake formation: results for exterior platform angle, platform depth, angle of blow, velocity, and force. Journal of Archaeological Science 36, 1945-1954 (2009).

60. Dibble, H. \& Whittaker, J. C. New experimental evidence on the relation between percussion flaking and flake variation. Journal of Archaeological Science 8, 283-296 (1981)

61. Speth, J. D. Mechanical basis of percussion flaking. American Antiquity 37, 34-60 (1972).

62. Speth, J. D. Experimental investigations of hard-hammer percussion flaking. Tebiwa 17, 7-36 (1974).

63. Speth, J. D. The role of platform angle and core size in hard-hammer percussion flaking. Lithic Technology 10, 16-21 (1981).

64. Wynn, T. \& Coolidge, F. L. Did a small but significant enhancement in working memory capacity power the evolution of modern thinking? In: Rethinking the Human Revolution, eds Mellars, P., Boyle, K., Bar-Yosef, O. \& Stringer C., pp. 79-90 (McDonald Institute for Archaeological Research, Cambridge, 2007).

65. Magnani, M. et al. Flake variation in relation to the application of force. Journal of Archaeological Science 46, 37-49 (2014).

66. Patten, B. Explaining temporal change in artifacts by the use of process controls. Lithic Technology 37, 25-34 (2012).

67. Huffman, G. G. Geology of the Ozark Uplift, northeastern Oklahoma. The Shale Shaker Digest I I-V, 36-42 (1955).

68. Thompson, T. L. Stratigraphy and Conodont Biostratigraphy of Kinderhookian and Osagean Rocks of Southwestern Missouri and Adjacent Areas (Missouri Geological Survey and Water Resources Rept Inv 45, 1970).

69. Banks, L. From Mountain Peaks to Alligator Stomachs: A Review of Lithic Sources in the Trans-Mississippi South, the Southern Plains, and Adjacent Southwest (Oklahoma Anthropological Society, Memoir 4 1990).

70. Lin, S. C., Rezek, Z., Braun, D. \& Dibble, H. L. On the utility and economization of unretouched flakes: the effects of exterior platform angle and platform depth. American Antiquity 78, 724-745 (2013).

71. Buchanan, B., Mraz, V. \& Eren, M. I. On identifying stone tool production techniques: an experimental and statistical assessment of pressure versus soft hammer percussion flake form. American Antiquity 81, 737-751 (2016).

72. Razali, N. M. \& Wah, Y. B. Power comparisons of Shapiro-Wilk, Komolgorov-Smirnov, Lilliefors, and Anderson-Darling tests. J. Statistical Modeling and Analytics 2, 21-33 (2011).

73. Benjamini, Y. \& Yekutieli, D. The control of false discovery rate under dependency. Annals of Statistics 29, 1165-1188 (2001).

74. Narum, S. R. Beyond Bonferroni: less conservative analyses for conservation genetics. Conservation Genetics 7, 783-787 (2006).

75. Bowman, A. W. \& Azzalini, A. R package 'sm': nonparametric smoothing methods (version 2.2-5.6) URL, http://www.stats.gla. ac.uk/ adrian/sm (2018)

76. R Development Core Team. R: A language and environment for statistical computing. R Foundation for Statistical Computing, Vienna, Austria, http://www.R-project.org (2018).

77. RStudio. RStudio: Integrated Development Environment for R (Version 1.1.456) [Computer software]. Boston. Available from, http://www.rstudio.org/ (2018).

\section{Acknowledgements}

V.M. and B.B. thank the University of Tulsa, Anthropology Department, the Odell Research Fellowship and the Odell High Risk Research Grant, and Office of Research Student Research Grants the University of Tulsa. M.I.E. thanks Dean James Blank and the College of Arts and Sciences at Kent State University.

\section{Author Contributions}

Mraz, Lovejoy, Eren, and Buchanan wrote the article. Mraz generated the data and Buchanan analyzed the data. Mraz, Fisch, Eren, and Buchanan designed the experiment. 


\section{Additional Information}

Supplementary information accompanies this paper at https://doi.org/10.1038/s41598-019-51139-3.

Competing Interests: The authors declare no competing interests.

Publisher's note Springer Nature remains neutral with regard to jurisdictional claims in published maps and institutional affiliations.

(c) (i) Open Access This article is licensed under a Creative Commons Attribution 4.0 International License, which permits use, sharing, adaptation, distribution and reproduction in any medium or format, as long as you give appropriate credit to the original author(s) and the source, provide a link to the Creative Commons license, and indicate if changes were made. The images or other third party material in this article are included in the article's Creative Commons license, unless indicated otherwise in a credit line to the material. If material is not included in the article's Creative Commons license and your intended use is not permitted by statutory regulation or exceeds the permitted use, you will need to obtain permission directly from the copyright holder. To view a copy of this license, visit http://creativecommons.org/licenses/by/4.0/.

(C) The Author(s) 2019 